www.jmscr.igmpublication.org
Impact Factor 3.79

ISSN (e)-2347-176x

crossref DOI: http://dx.doi.org/10.18535/jmscr/v3i9.44

Journal Of Medical Science And Clinical Research

\title{
Study and Analysis of Audiometer Signal
}

\author{
Authors \\ Subiya Fatima ${ }^{1}$, Dr. Channappa Bhyri ${ }^{2}$, Prof. Kalpana Vanjerkhede ${ }^{3}$ \\ ${ }^{1}$ PG Student PDA Engineering College Kalaburagi \\ Email: 'subiya29@yahoo.com \\ ${ }^{2}$ Asso. Professor Department of Instrumentation Technology, PDACEG \\ Email: ${ }^{2}$ channubhyri@yahoo.com \\ ${ }^{3}$ HOD IT PDA College of Engineering, Kalaburagi \\ Email: ${ }^{3}$ hodit@pdaengg.com
}

\begin{abstract}
The objective of the work is to determine the type of hearing loss of an individual and plot the frequency and intensity recording and construct the audiogram. In this work microprocessor controlled clinical diagnostic Audiometer has been used for measuring hearing loss. The audiogram is a chart of hearing sensitivity with frequency charted on the $X$-axis and intensity on the Y-axis. The audiogram is a graph which gives a detailed description of your hearing ability. Two different processes are used in pure tone audiometer, one is air conduction and the other is bone conduction to identify hearing loss. Subjects were tested by varying the frequency and intensity with the proposed system and test results were analyzed using statistical method.

Keywords-Air conduction, Bone Conduction, Frequency, Hearing loss, Intensity.
\end{abstract}

\section{INTRODUCTION}

\section{Anatomy of the Ear}

The ear is made up of three parts: the outer, middle, and inner ear. All three parts of the ear are important for detecting sound by working together to move sound from the outer part through the middle and into the inner part of the ear. Ears also help to maintain balance. The anatomy of ear is shown in figure 1.

\section{The Outer Ear}

The outer ear includes, auricle (cartilage covered by skin placed on opposite sides of the head), auditory canal (also called the ear canal), and eardrum outer layer (also called the tympanic membrane). The outer part of the ear collects sound. Sound travels through the auricle and the auditory canal, a short tube that ends at the eardrum.

\section{The middle Ear}

The middle ear includes, eardrum, cavity (also called the tympanic cavity), ossicles (3 tiny bones that are attached).the 3bones are malleus (or hammer) long handle attached to the eardrum, incus (or anvil) - the bridge bone between the malleus and the stapes, stapes (or stirrup) - the footplate; the smallest bone in the body. Sound entering the outer ear travels through the middle ear and causes the 
eardrum and ossicles in the middle ear to vibrate. As it travels, it amplifies (becomes louder) and changes from air to liquid.

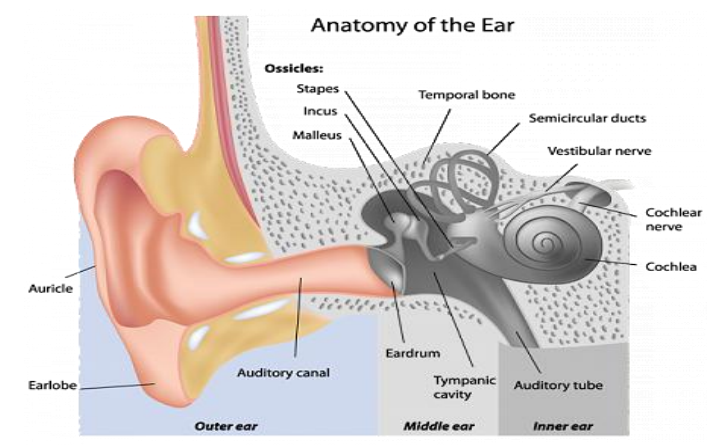

Figure 1. Anatomy of Ear

\section{The Inner Ear}

The inner ear includes, oval window - connects the middle ear with the inner ear, semicircular ducts filled with fluid, attached to cochlea and nerves, cochlea - spiral-shaped organ of hearing, transforms sound into signals that get sent to the brain, auditory tube - drains fluid from the middle ear into the throat behind the nose. When the stapes moves, it pushes the oval window, which then moves the cochlea. The cochlea takes the fluid vibration of sounds from the surrounding semicircular ducts and translates them into signals that are sent to the brain by nerves like the vestibular nerve and cochlear nerve.

\section{METHODOLOGY}

\section{Audiometer}

Pure tone audiometer is the most common type of hearing test. This type of test results in an audiogram. Ear phones are applied which are color coded (Red for right ear, Blue for left ear). Start with a frequency of $125 \mathrm{~Hz}$. \& $0 \mathrm{~dB}$. Gradually increase the $\mathrm{dB}$ till person hears the sound \& respond. Mark the threshold intensity on the audiogram paper. Find the threshold of hearing from $125 \mathrm{~Hz}$. to $8000 \mathrm{~Hz}$. \& mark on the audiogram paper. Join the points to make air conduction audiogram. Place the bone vibrator over the mastoid process. Deliver the sound through the vibrator \& find out the threshold of hearing for different frequencies of sound. Use different sign to mark the bone conduction audiogram. Select the other ear and repeat the whole procedure.

Air Conduction Audiometer: In the air conduction audiometer test, subject will be asked to listen to a series of sounds through a set of headphones and indicate when the subject hears a sound by pressing a button. The sounds are at different frequencies (pitch) and different intensities (levels of loudness).This process tests subject ability to hear sounds entering through the outer ear to the entire hearing system. Each ear is tested separately and the softest sounds heard at each frequency are plotted on a graph called an audiogram.

Bone Conduction Audiometer: Bone conduction audiometer tests involve placing a small vibrator on the bone immediately behind the ear. These sounds travel through the bones of the skull to the cochlea and hearing nerves - effectively bypassing the outer and middle ear. Again, you will be asked to indicate which test sounds you can hear and these results are added to the audiogram.

\section{Audiogram}

The audiogram is a graph which gives a detailed description of hearing ability and which can be described as a picture of sense of hearing. The audiogram illustrates hearing ability by showing hearing threshold at various frequencies. Hearing threshold is an indication of how soft a sound may get before it is inaudible. A hearing threshold of between 0 and $25 \mathrm{~dB}$ is considered as normal.

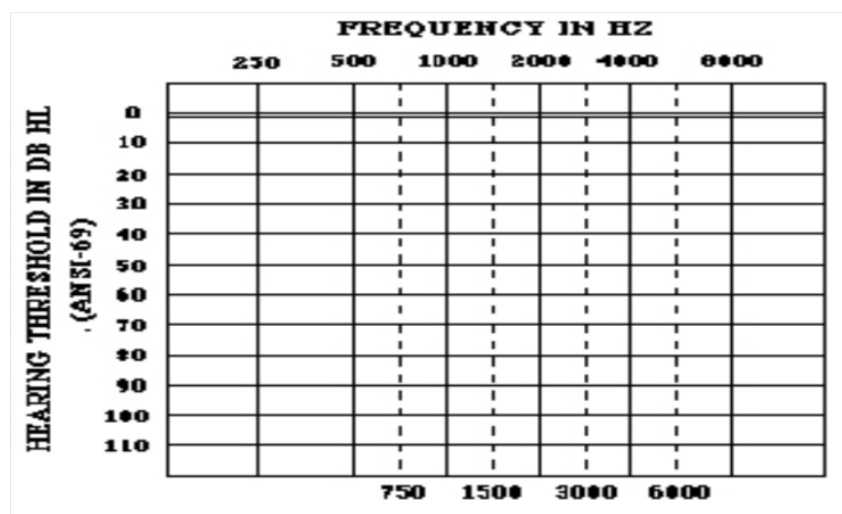

Figure 2. Audiogram 
The audiogram is shown in figure 2. The vertical axis of the audiogram represents sound volume or intensity which is measured in decibels $(\mathrm{dB})$. The more one moves down the axis, the louder the sound becomes. The horizontal axis of the audiogram represents sound frequency or pitch measured in Hertz $(\mathrm{Hz})$. Sound frequency increases gradually the further one moves to the right along the axis.

\section{Degrees of hearing loss:}

- Normal hearing (0-25 dB)

- Mild hearing loss (26-40 dB)

- Moderate hearing loss (41-55 dB)

- Moderate-severe hearing loss (56-70 dB)

- Severe hearing loss (71-90 dB)

- Profound hearing loss (>90 dB)

\section{TYPES OF HEARING LOSS CONDUCTIVE HEARING LOSS:}

If a patient has a disorder of the outer and/or middle ear ONLY, then AC thresholds will be abnormal in the presence of normal BC thresholds. Air-bone gap $=$ greater than or equal to $15 \mathrm{~dB}$ difference between $\mathrm{AC}$ and $\mathrm{BC}$. This is called a conductive hearing loss (CHL), as sound cannot properly conduct through the outer and/or middle ear to reach the normalhearing cochlea. The audiogram of conductive hearing loss is shown in figure 3.

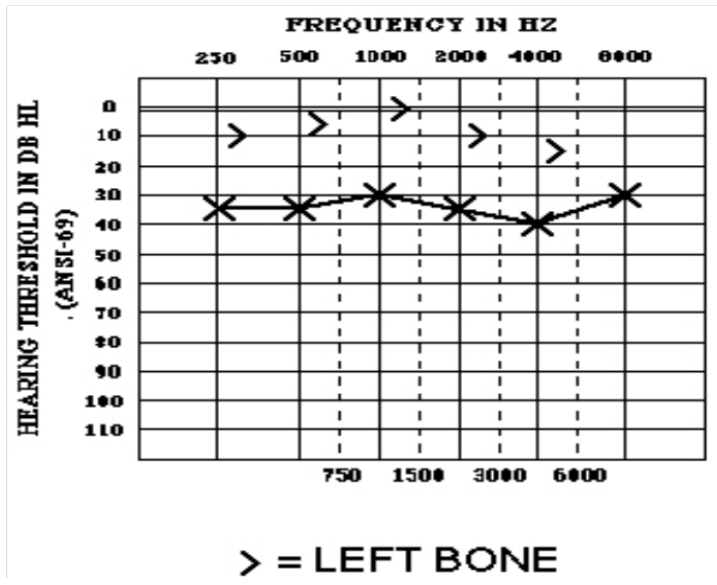

Figure 3. Conductive Hearing Loss

\section{SENSORINEURAL HEARING LOSS:}

If a patient has a disorder of the inner ear and/or auditory nerve, then $\mathrm{AC}$ thresholds will be equal to BC thresholds (no air-bone gap) and both will be abnormal. This is called a sensor neural hearing loss (SNHL). The audiogram of sensorineural hearing loss is shown in figure 4.

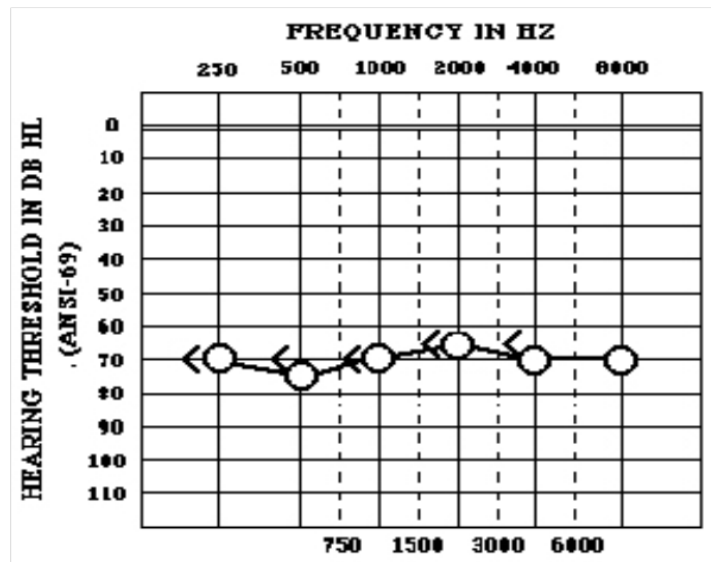

Figure 4.Sensorineural Hearing Loss

\section{MIXED HEARING LOSS:}

If a patient has a disorder of the inner ear and/or auditory nerve AND an outer/middle ear disorder, then both $\mathrm{AC}$ thresholds and $\mathrm{BC}$ thresholds will be abnormal AND an air-bone gap will exist .This is called a mixed hearing loss. The audiogram of mixed hearing loss is shown in figure 5.

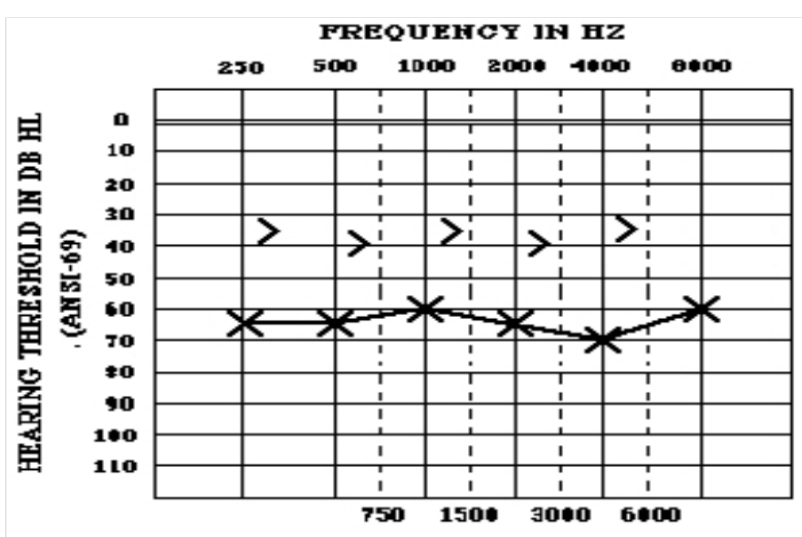

Figure 5. Mixed Hearing Loss 
Table 1: Statistical data of normal subjects

\begin{tabular}{|c|c|c|c|c|c|c|c|c|c|c|c|c|c|c|c|c|}
\hline \multirow[t]{2}{*}{ Sl.no } & \multicolumn{4}{|c|}{ ACR } & \multicolumn{4}{|c|}{ BCR } & \multicolumn{4}{|c|}{ ACL } & \multicolumn{3}{|c|}{ BCL } & \multirow[b]{2}{*}{ MAX } \\
\hline & MEAN & SD & MIN & MAX & MEAN & SD & MIN & MAX & MEAN & SD & MIN & MAX & MEAN & SD & MIN & \\
\hline 1 & 39 & 11.5 & 25 & 55 & 22 & 6.32 & 10 & 30 & 40 & 7.82 & 30 & 50 & 20 & 7.45 & 10 & 30 \\
\hline 2 & 35 & 5.4 & 25 & 45 & 26.36 & 5.51 & 20 & 35 & 31.36 & 3.93 & 25 & 35 & 21.81 & 6.03 & 10 & 30 \\
\hline 3 & 26.81 & 11.6 & 10 & 40 & 16 & 6.5 & 5 & 30 & 23.63 & 10.26 & 10 & 40 & 11.25 & 5.17 & 5 & 20 \\
\hline 4 & 20 & 7.41 & 10 & 30 & 11.1 & 4.85 & 5 & 20 & 25.9 & 10.2 & 10 & 40 & 16 & 6.58 & 5 & 30 \\
\hline 5 & 32.72 & 11.6 & 15 & 50 & 21 & 9.36 & 5 & 35 & 32.27 & 9.04 & 15 & 45 & 22 & 8.8 & 10 & 35 \\
\hline 6 & 32.27 & 9.58 & 20 & 50 & 16 & 6.58 & 5 & 30 & 27.27 & 11.03 & 10 & 45 & 21.5 & 8.18 & 15 & 35 \\
\hline 7 & 33.63 & 10.02 & 15 & 45 & 17.5 & 6.34 & 5 & 30 & 28.18 & 11.01 & 10 & 45 & 19.5 & 5.50 & 15 & 30 \\
\hline 8 & 26.81 & 9.5 & 10 & 40 & 16.5 & 6.68 & 5 & 30 & 34.09 & 8 & 20 & 45 & 21.5 & 8.18 & 15 & 35 \\
\hline 9 & 32.27 & 11.26 & 20 & 55 & 16 & 6.58 & 5 & 30 & 22.72 & 7.19 & 10 & 30 & 19.5 & 5.5 & 15 & 30 \\
\hline 10 & 30 & 7.07 & 20 & 40 & 21 & 9.36 & 5 & 35 & 26.36 & 8.09 & 15 & 45 & 11.25 & 5.17 & 5 & 20 \\
\hline
\end{tabular}

Table 2: Statistical data of abnormal subjects

\begin{tabular}{|c|c|c|c|c|c|c|c|c|c|c|c|c|c|c|c|c|}
\hline Sl.No & \multicolumn{4}{|c|}{ ACR } & \multicolumn{4}{|c|}{ BCR } & \multicolumn{4}{|l|}{ ACL } & \multicolumn{4}{|c|}{ BCL } \\
\hline & MEAN & SD & MIN & MAX & MEAN & SD & MIN & MAX & MEAN & SD & MIN & MAX & MEAN & SD & MIN & MAX \\
\hline 1 & 66.6 & 12.9 & 50 & 85 & 38 & 5.7 & 30 & 45 & 67.5 & 8.8 & 55 & 80 & 44 & 4.1 & 40 & 50 \\
\hline 2 & 47.5 & 4.37 & 40 & 52 & 6.4 & 3.5 & 2 & 10 & 9.8 & 4.4 & 5 & 18 & 2 & 4.4 & 0 & 10 \\
\hline 3 & 15.83 & 5.4 & 10 & 25 & 2 & 2.7 & 0 & 5 & 17.1 & 6.7 & 10 & 25 & 4.4 & 4.3 & 0 & 10 \\
\hline 4 & 76.6 & 10.8 & 60 & 90 & 50.6 & 8.3 & 45 & 65 & 84.1 & 9.7 & 75 & 100 & 56 & 6.5 & 50 & 65 \\
\hline 5 & 33 & 11.4 & 20 & 45 & 29.6 & 7.3 & 20 & 38 & 46.8 & 13 & 35 & 70 & 40 & 10 & 40 & 55 \\
\hline 6 & 93.3 & 4.08 & 90 & 100 & 60.6 & 6.8 & 50 & 68 & 58.3 & 15 & 40 & 80 & 46 & 13 & 30 & 65 \\
\hline 7 & 18.5 & 5.04 & 10 & 25 & 11 & 4.1 & 5 & 15 & 17.1 & 6 & 10 & 25 & 3 & 2.7 & 0 & 5 \\
\hline 8 & 78.3 & 12.1 & 65 & 95 & 58.6 & 5.4 & 50 & 65 & 50.8 & 7.3 & 45 & 60 & 43 & 4.4 & 40 & 50 \\
\hline 9 & 26.6 & 6.83 & 15 & 35 & 16 & 4.1 & 10 & 20 & 31.6 & 7.5 & 25 & 40 & 24 & 5.4 & 20 & 30 \\
\hline 10 & 12.5 & 2.7 & 10 & 15 & 3 & 2.7 & 0 & 5 & 13.6 & 2.1 & 10 & 15 & 8 & 2.7 & 5 & 10 \\
\hline 11 & 35.8 & 9.17 & 25 & 50 & 24 & 5.4 & 20 & 30 & 40.8 & 7.3 & 35 & 50 & 33 & 4.4 & 30 & 40 \\
\hline 12 & 20 & 8.3 & 10 & 30 & 9 & 6.5 & 15 & 45 & 32.5 & 5.2 & 25 & 40 & 6 & 4.2 & 0 & 10 \\
\hline 13 & 59.1 & 7.3 & 50 & 70 & 33 & 2.7 & 30 & 35 & 76.6 & 9.8 & 65 & 90 & 51 & 4.2 & 45 & 55 \\
\hline 14 & 80.8 & 9.7 & 65 & 90 & 52 & 2.7 & 50 & 55 & 20.8 & 9.7 & 10 & 35 & 8 & 5.7 & 0 & 15 \\
\hline 15 & 24.16 & 6.6 & 15 & 35 & 20 & 4 & 15 & 25 & 33.3 & 4 & 30 & 40 & 28 & 2.7 & 25 & 30 \\
\hline 16 & 32.5 & 4.18 & 30 & 40 & 13.75 & 2.5 & 10 & 15 & 20 & 7 & 10 & 30 & 6 & 4.1 & 0 & 10 \\
\hline 17 & 28.3 & 5.16 & 20 & 35 & 5 & 3.5 & 0 & 10 & 35.8 & 9.1 & 25 & 50 & 13 & 2.7 & 10 & 15 \\
\hline 18 & 20.83 & 6.64 & 10 & 30 & 5 & 3.5 & 0 & 10 & 16.6 & 6 & 10 & 25 & 6 & 4.1 & 0 & 10 \\
\hline 19 & 80 & 10 & 65 & 90 & 57 & 9 & 45 & 70 & 17.5 & 6.8 & 10 & 25 & 12 & 5.7 & 5 & 20 \\
\hline 20 & 55.8 & 10.6 & 45 & 75 & 43 & 4.4 & 40 & 50 & 70.8 & 11 & 60 & 90 & 48 & 7.5 & 40 & 60 \\
\hline
\end{tabular}

Table 3: Statistical data of cancer subjects

\begin{tabular}{|l|l|}
\hline Cancer subjects & Audiometer tests \\
\hline Mean & 109.8 \\
\hline Standard deviation & 87 \\
\hline Minimum & 29 \\
\hline Maximum & 364 \\
\hline
\end{tabular}

Table 4: Comparison of statistical data

\begin{tabular}{|l|l|l|l|}
\hline & $\begin{array}{l}\text { Normal } \\
\text { subjects }\end{array}$ & $\begin{array}{l}\text { Abnormal } \\
\text { subjects }\end{array}$ & $\begin{array}{l}\text { Cancer } \\
\text { subjects }\end{array}$ \\
\hline Mean & 39 & 66.6 & 109.8 \\
\hline Standard deviation & 11.5 & 12.9 & 87 \\
\hline Minimum & 25 & 50 & 29 \\
\hline Maximum & 55 & 85 & 364 \\
\hline
\end{tabular}

\section{RESULTS AND DISCUSSION}

The hearing loss has been acquired from the subjects by varying the frequency and intensity of the audiogram. Hearing loss is analysed by statistical method and the mean, standard deviation, minimum and maximum values are determined. Table 1 shows the statistical data of normal subjects with normal hearing and mild hearing loss, considering subject1 the mean value is 39 , standard deviation is 11.5 , minimum value is 25 and maximum value is 55 for air conduction.

Table 2 shows the statistical data of abnormal subjects with different types of hearing losses, considering subject 1 the values are increased compared to table 1 , such as the mean is 66.6, standard deviation is 12.9 , minimum value is 50 and maximum value is 85 of air conduction. In this way 10 normal subjects and 20 abnormal subjects are analysed statistically by varying the frequency and intensity of air conduction left ear and right ear and bone conduction left ear and right ear. 
Table 3 shows the statistical data of cancer subjects accumulating cisplatin drug, the values are increased compared to normal subjects.

Table 4 shows the comparison of normal, abnormal and cancer subjects data.

\section{CONCLUSION}

By using the microprocessor controlled clinical diagnostic audiometer the hearing loss of normal, abnormal, and cancer subjects is determined by varying frequency and intensity of the audiogram. The hearing loss of the subjects is analyzed by statistical method and the mean, standard deviation, minimum, and maximum values are determined. It is observed that the abnormal and cancer subjects Statistical parameter values are increased compared to normal subjects. Hence the statistical data of different types of hearing loss is analyzed.

\section{REFERENCES}

1. Yeou-Jiunn Chen, "Develop an objective measure mechanism to analyze speech discrimination of sensorineural hearing loss," Biomedical Engineering, 2003. IEEE EMBS Asian-Pacific Conference on, vol., no., pp.352, 353, 20-22 Oct. 2003

2. Jacobs, P.G.; Silaski, G.; Wilmington, D.; Gordon, S.; Helt, W.; McMillan, G.; Fausti, S.A.; Dille, M., "Development and Evaluation of a Portable Audiometer for High-Frequency Screening of Hearing Loss From Ototoxicity in Homes/Clinics," Biomedical Engineering, IEEE Transactions on, vol.59, no.11, pp.3097,3103, Nov. 2012

3. Chalupper,J.; Fastl, H., "Simulation of hearing impairment based on the Fourier time transformation," Acoustics, Speech, and Signal Processing, 2000. ICASS '00.Proceedings. 2000 IEEE International Conference on, vol.2, no., pp.II857,II860 vol.2, 2000
4. Fernandez, A.; Penedo, M.G.; Ortega, M.; Cancela, B.; Vazquez, C.; Gigirey, L.M., "Automatic Analysis of the Patient's Conscious Responses to the Emission of Auditory Stimuli during the Performance of an Audiometry," Digital Image Computing Techniques and Applications (DICTA), 2011 International Conference on, vol., no., pp.291,296, 6-8 Dec. 2011

5. Yuhao Wu; JiaJia; Xiulong Zhang; LianhongCai, "Algorithm of pure tone audiometry based on multiple judgment," Chinese Spoken Language Processing (ISCSLP), 2014 9th International Symposium on, vol., no., pp.398,398, 12-14 Sept. 2014

6. Tsuge, S.; Koizumi, D.; Fukumi, M.; Kuroiwa, S., "Speaker verification method using bone-conduction and air-conduction speech," Intelligent Signal Processing and Communication Systems, 2009.ISPACS 2009. International Symposium on, vol., no., pp.449,452, 7-9 Jan. 2009

7. Rahman, M.S.; Shimamura, T., "A study on amplitude variation of bone conducted speech compared to air conducted speech," Signal and Information Processing Association Annual Summit and Conference (APSIPA), 2013 Asia-Pacific, vol., no., pp.1,5, Oct. 29 2013-Nov. 12013

8. S. Rajkumar1, S. Muttan2, V. Jaya3 and S. S. Vignesh "Hearing Loss Assessment And Analysis Of Hearing Impaired Subjects Using a Facile Audiometric Technique "ARPN Journal of Engineering and Applied Sciences VOL. 10, NO. 1, JANUARY 2015

9. Dayna S. Dalton, MS,1 Karen J. Cruickshanks, PhD,1,2 Barbara E. K. Klein, MD,Ronald Klein, MD, 1 Terry L. Wiley, $\mathrm{PhD}, 3$ and David M. Nondahl, MS "The Impact of Hearing Loss on Quality of Life in Older Adults" The Gerontologist Copyright 2003 by The Gerontological Society of America Vol. 43, No. 5, 661-668. 